\title{
ULOGA MEDICINSKE SESTRE U ZDRAVSTVENOJ NJEZI BOLESNIKA NA HEMODIJALIZI
}

\author{
Julija Krstanović, Roberta Perković, Joško Petričević \\ Fakultet zdravstvenih studija Sveučilišta u Mostaru, Mostar, Bosna i Hercegovina \\ Rad je primljen 17.09.2018. Rad je recenziran 1.10.2018. Rad je prihvaćen 9.11.2018
}

\section{SAŽETAK}

UVOD: Zahvaljujući velikom napretku u liječenju hemodijalizom, bolesnici s kroničnim zatajenjem bubrega danas mogu živjeti dulje i kvalitetnije. Kvalitetna suradnja, bolesnikova prilagodba i učinkovito pridržavanje zdravstvenih preporuka temelj su za kvalitetan proces hemodijalize sa minimalnom pojavom komplikacija.

CILJ: Cilj rada bio je pregledom različitih istraživanja prikazati utjecaj pravilnog provođenja zdravstvene njege bolesnika na hemodijalizi na kvalitetu procesa hemodijalize i pojavnost komplikacija.

ISPITANICI I METODE: Korištena je sljedeća metodologija: pretraživanje biomedicinske baze podataka PubMed i pregled novijih istraživanja u zadnjih 5 godina korištenjem baze podataka Google znalac. Selekcijom radova koristeći ključne riječi u naslovu i sažetku izvršena je analiza 9 kliničkih istraživanja.

REZULTATI: U većini nefroloških odjela odsutne su smjernice o pružanju skrbi za hemodijalizne pacijente. Seksualna disfunkcija je poteškoća o kojoj se malo govori, a edukacija zdravstvenih profesionalaca pridonijela bi rješavanju poteškoća. Nesuradljivost prilikom uzimanja lijekova i razvoj kognitivnih poremećaja česti su problemi hemodijaliziranih bolesnika. ZAKLJUČAK: Podrška u zajednici, a ponajprije obitelji, izrazito su važan izvor potpore pacijentima na hemodijalizi. Zdravstveni sustav treba omogućiti oboljelim što veći stupanj neovisnosti, razvoj vještina samopomoći i mehanizama suočavanja sa svim negativnim posljedicama liječenja.

Ključne riječi: medicinska sestra, zdravstvena skrb, hemodijaliza i pacijent.

Osoba za razmjenu informacija:

Julija Krstanović, prvostupnik sestrinstva

E-mail: krstanović.juluja93@gmail.com

\section{UVOD}

Hemodijaliza je postupak pomoću kojeg se iz krvi uremičara uklanjaju razgradni produkti metabolizma (toksini), elektroliti koji su u suvišku (kalij) i voda, a istovremeno se dodaju organizmu potrebne supstancije (1). Zahvaljujući velikom napretku u liječenju hemodijalizom, bolesnici s kroničnim zatajenjem bubrega danas mogu živjeti dulje i kvalitetnije (2). Kvalitetna suradnja, bolesnikova prilagodba i učinkovito pridržavanje zdravstvenih preporuka temelj su za kvalitetan proces hemodijalize sa minimalnom pojavom komplikacija (3). Kod pacijenata koji se liječe uporabom metode hemodijalize jedna od najučestalijih komplikacija je pojava anksioznosti. Rezultatima istraživanja provedenog u Općoj bolnici u Ogulinu utvrđen je najveći postotak jako tjeskobnih hemodijaliziranih pacijenata $\mathrm{u}$ istraživanom uzorku (4). Učinkovitost programa treninga disanja za smanjenje depresije kod bolesnika na hemodijalizi i poboljšanja kvalitete spavanja testirana je u studiji na uzorku od 57 pacijenata podijeljenih u dvije grupe, intervencijsku i kontrolnu. Intervencijska skupina je prolazila program treninga disanja za smanjenje depresije. Intervencijska skupina je statistički značajno ublažila depresivne simptome, smanjila emocionalne probleme i poboljšala ukupnu mentalnu zdravstvenu komponentu (5). Za bolesnike na hemodijalizi vrlo je važan emocionalni odnos između bolesnika i medicinskog osoblja. Strah kod ovih bolesnika uvijek je prisutan, stoga je potrebno pobuditi sigurnost i međusobno povjerenje (6). 
Mjerenje kvalitete života kod hemodijaliznih bolesnika ima značajnu prediktivnu vrijednost na preživljavanje i hospitalizaciju (7). Pregledom literature baza podataka Medline i Ebsco za razdoblje 2005.2016. godine utvrdilo se da je u bolesnika na dijalizi kvaliteta života značajno niža u odnosu na opću populaciju (8). Istraživanje provedeno 2012. godine u Teheranu, u vojnoj bolnici kod 32 pacijenta koji su se liječili hemodijalizom, utvrđivalo je učinke korištenja self-care modela za zdravlje i kvalitetu života. Rezultati su pokazali da su se sve dimenzije kvalitete života (fizička funkcija, vitalnost, opće zdravlje i mentalno zdravlje) poboljšale s obzirom na prijašnju intervenciju (9). Cilj ovog rada bio je pregledom različitih istraživanja prikazati utjecaj pravilnog provođenja zdravstvene njege bolesnika na hemodijalizi na kvalitetu procesa hemodijalize i pojavnost komplikacija.

\section{ISPITANICI I METODE}

U svrhu istraživanja utjecaja važnosti pravilnog i kvalitetnog provođenja zdravstvene njege bolesnika na hemodijalizi, korištena je sljedeća metodologija:
1. Učinjeno je pretraživanje biomedicinske baze podataka PubMed. Ključne riječi za pretraživanje bile su na engleskom jeziku: role and nursing care (uloga i skrb sestre), patient (pacijent) i hemodialysis (hemodijaliza). Uz ključne riječi kriteriji uključenja bili su: clinical trials (klinička istraživanja) i year of publication (godina objave) 2013.-2018.

2. Pregled novijih istraživanja u zadnjih 5 godina korištenjem baze podataka Google znalac. Ključne riječi za pretraživanje bile su na hrvatskom jeziku: uloga i skrb sestre, pacijent i hemodijaliza.

\section{REZULTATI}

Slijedeći opisanu metodologiju nađeno je 97 kliničkih istraživanja na PubMedu. Selekcijom radova koristeći ključne riječi u naslovu i sažetku izvršena je analiza 5 kliničkih istraživanja. Pretraživanjem ključnih riječi na Google znalac pronađeno je 196 rezultata, a izvršena je analiza 4 klinička istraživanja na osnovu kriterija godine objavljivanja.

Tablica 1. Istraživanja uključena u analizu

\begin{tabular}{|c|c|c|c|c|c|}
\hline $\begin{array}{l}\text { Autori; } \\
\text { Godina izdavanja }\end{array}$ & Cilj & Tip & Broj ispitanika & Zemlja & Rezultati \\
\hline Gawi A i sur., 2017. & $\begin{array}{l}\text { Utvrditi ulogu med. sestre } \\
\text { u pružanju seksualne skrbi } \\
\text { pacijentima na HD }\end{array}$ & Presječna studija & $N=1211$ & Nizozemska & $\begin{array}{l}\text { Istraživanje ukazuje da bi } \\
\text { sestre trebale proći dodatne obuke i koristiti smjernice } \\
\text { za bolje pružanje usluga } \\
\text { skrbi. }\end{array}$ \\
\hline Krouwel EM i sur., 2017. & $\begin{array}{l}\text { Procjena skrbi sestara i nefrologa } \\
\text { u pružanju njege bolesnika s CKD- } \\
\text { om na odjelu HD }\end{array}$ & $\begin{array}{l}\text { Presječna } \\
\text { studija }\end{array}$ & $N=1523$ & Nizozemska & $\begin{array}{l}\text { Odsutno je pružanje skrbi i edukacije pacijenata od } \\
\text { strane med. sestara i nefrologa o plodnosti na odjelu } \\
\text { za HD. }\end{array}$ \\
\hline $\begin{array}{l}\text { Vioulac C i sur., } \\
2016 .\end{array}$ & $\begin{array}{l}\text { Istražiti koncept empatije i stresa } \\
\text { kod } \\
\text { med. sestara na } \\
\text { odjelu HD }\end{array}$ & $\begin{array}{l}\text { Kvalitativna } \\
\text { studija }\end{array}$ & $N=23$ & Francuska & $\begin{array}{l}\text { Rezultati su pokazali da je potrebno preciznije } \\
\text { istraživati utjecaj stresa i empatije iskustvo s obzirom } \\
\text { na med. sestara i njihov utjecaj na pacijente. }\end{array}$ \\
\hline $\begin{array}{l}\text { Farias de } \\
\text { Queiroz Frazao } \\
\text { CM i sur., } 2015 .\end{array}$ & $\begin{array}{c}\text { Procijeniti sličnost } \\
\text { između NANDA i } \\
\text { Rovjevog modela prilagodbe kod } \\
\text { bolesnika koji su podvrgnuti HD. }\end{array}$ & $\begin{array}{l}\text { Presječna } \\
\text { studija }\end{array}$ & $\mathrm{N}=178$ & Brazil & $\begin{array}{l}\text { Utvrdena je sličnost između NANDA i Rovjevog model } \\
\text { prilagodbe. }\end{array}$ \\
\hline $\begin{array}{l}\text { Saunders Si } \\
\text { sur., } 2015 .\end{array}$ & $\begin{array}{l}\text { Utvrditi uporabu } \\
\text { protokola upravljanja } \\
\text { kod sestara pri } \\
\text { liječenju anemičara } \\
\text { na HD }\end{array}$ & $\mathrm{RKS}^{*}$ & $N=107$ & Kanada & $\begin{array}{l}\text { Uporaba protokola pri } \\
\text { liječenju anemije je djelotvorna i pridonosi } \\
\text { sigurnom ishodu } \\
\text { pacijenata. }\end{array}$ \\
\hline
\end{tabular}


Krstanović J, Perković R, Petričević J. Uloga medicinske sestre u zdravstvenoj njezi bolesnika na hemodijalizi. Zdravstveni glasnik. 2018;2:44-49.

\begin{tabular}{|c|c|c|c|c|c|}
\hline Raguž D., 2014. & $\begin{array}{l}\text { Istražiti učestalost } \\
\text { javljanja i vrstu SMP kod bolesnika } \\
\text { na HD }\end{array}$ & $\begin{array}{l}\text { Presječna } \\
\text { studija }\end{array}$ & $\mathrm{N}=35$ & Hrvatska & $\begin{array}{l}\text { Više od pola ispitanika imalo je SMP; Najěčšci su } \\
\text { bili: hipotenzija i } \\
\text { hipertenzija. }\end{array}$ \\
\hline $\begin{array}{l}\text { Logarušić D., } \\
2016 .\end{array}$ & $\begin{array}{l}\text { Istražiti kognitivni } \\
\text { status bolesnika na } \\
\text { HD pomoću MoCa } \\
\text { test. }\end{array}$ & $\begin{array}{l}\text { Presječna } \\
\text { studija }\end{array}$ & $\mathrm{N}=100$ & Hrvatska & $\begin{array}{l}\text { Rezultati su pokazali da je } \\
\text { KP utvrđen kod više od } \\
\text { pola pacijenata i da svaka } \\
\text { godina života povećava } \\
\text { rizik za } 19 \% \text {. }\end{array}$ \\
\hline Bart D., 2017. & $\begin{array}{l}\text { Utvrditi učestalost } \\
\text { nesuradljivosti pri } \\
\text { uzimanju lijekova u } \\
\text { bolesnika na HD. } \\
\end{array}$ & $\begin{array}{l}\text { Presječna } \\
\text { studija }\end{array}$ & $\mathrm{N}=127$ & Hrvatska & $\begin{array}{l}\text { Rezultati su pokazali da su bolesnici na HD nesuradljivi } \\
\text { prilikom uzimanja lijekova u otprilike trećini slučajeva. }\end{array}$ \\
\hline $\begin{array}{l}\text { Mateljić R., } \\
2014 .\end{array}$ & $\begin{array}{l}\text { Istražiti prehrambene navike } \\
\text { bolesnika na HD te konzumiranje } \\
\text { preporučenih i nepreporučenih } \\
\text { namirnica. }\end{array}$ & $\begin{array}{l}\text { Presječna } \\
\text { studija }\end{array}$ & $\mathrm{N}=130$ & Hrvatska & $\begin{array}{l}\text { Rezultati su pokazali da je potreban individualni pristup } \\
\text { pacijentu zbog nutritivnih potreba svakoga pacijenta. }\end{array}$ \\
\hline
\end{tabular}

Legenda: ${ }^{\star}$ RKS- randomizirana kontrolirana studija

\section{RASPRAVA}

Nefrološko okruženje promijenilo se u zadnjih 45 godina, pruža se više mogućnosti za pacijente i upotrebljava se sigurnija i naprednija tehnologija te postoji daljnja želja za unapređenjem. Nefrološka skrb temelji se na pacijentu i obitelji, na fiziološkim i psihosocijalnim potrebama (10).

Pregledom literature pokazalo se da su u većini odjela za nefrologiju odsutne smjernice o pružanju skrbi za hemodijalizne pacijente i da je jedan od najčešćih problema pacijenata seksualna disfunkcija o kojoj se rijetko govori.

Presječna studija provedena u Nizozemskoj na uzorku od 1211 ispitanika je istraživala ulogu medicinskih sestara na odjelu hemodijalize o edukaciji seksualne skrbi. Vrijeme provedbe ispitivanja bilo je od siječnja do svibnja 2016. godine, a stopa odgovora bila je 45,6\%. Tri četvrtine medicinskih sestara razgovaralo je o seksualnoj disfunkciji s manje od pola svojih pacijenta. Glavne prepreke za savjetovanje pacijenata su bile: etične dvojbe (57,3\%), kultura i religija $(54,1 \%)$ te starija dob pacijenata $(49,7 \%)$. Oko 18 \% sestara imalo je dovoljno znanja o problemima spolne disfunkcije kod hemodijaliznih pacijenata, a $68,3 \%$ je pokazalo potrebu za edukacijom, te njih $43 \%$ je znalo neke smjernice o pružanju seksualne skrbi (11). Istraživanjem na uzorku od 312 nefrologa i 1211 medicinskih sestara procjenjivala se uloga nefrologa i medicinskih sestara u pružanju edukacije o plodnosti pacijenata na hemodijalizi. Utvrđena je statistički značajna odsutnost u pružanju brige za probleme sa plodnošću kod pacijenata. Zaključeno je postojanje potrebe za smjernicama o ovom problemu, osposobljavanjem i edukacijom zdravstvenih djelatnika (12). Kvalitativna studija u Francuskoj istraživala je utjecaj empatije i stresa na medicinske sestre koje rade na odjelu za hemodijalizu. Istraživanje je provedeno 2014. godine i sudjelovale su 23 medicinske sestre. Kao stresori su navedeni: vrijeme $14 \%$, izvanredni događaji $12 \%$ te vrsta zadataka $8 \%$. Pokazalo se da je potrebno preciznije istražiti utjecaj stresa i empatije, osobito s obzirom na iskustvo medicinskih sestara i njihov utjecaj na pacijente (13). Presječna studija u Brazilu na uzorku od 178 ispitanika imala je za cilj usporediti NANDA model internacionalne dijagnostike $u$ sestrinstvu $i$ Royjev model prilagodbe kod pacijenata podvrgnutih hemodijalizi. Za prikupljanje podataka korišten je obrazac za razgovor i fizičku procjenu. Rezultati su pokazali sličnost između 20 dijagnosticiranih sestrinskih sustava i 22 problema prilagodbe (14). Randomizirana kontrolirana studija u Kanadi istraživala je korištenje protokola upravljanja pri liječenju anemije kod pacijenata na hemodijalizi. Sudjelovalo je 107 ispitanika podijeljenih u dvije skupine: kontrolna $(n=64)$ i intervencijska $(n=43)$. Intervencijska skupina koristila je protokol upravljanja 
bubrežnom anemijom, a kontrolna skupina tradicionalni pristup liječenju. Obje skupine postigle su ciljane razine hemoglobina. Razina transferina bila je veća u intervencijskoj skupini. Uporaba i troškovi željeza bili su veći u kontrolnoj, a uporaba eritropoetina bila je veća u intervencijskoj (15). Istraživanjem iz 2014. na Kliničkom odjelu za nefrologiju i dijalizu KBC-a Split mjerila se učestalost javljanja sestrinsko medicinskih problema kod bolesnika liječenih hemodijalizom. Od 35 ispitanih, njih 65,7 \% je razvilo sestrinsko medicinske probleme i to više ženskih u odnosu na muške ispitanike (16). Presječna studija u KBC-u Osijek utvrđivala je kognitivni status bolesnika na hemodijalizi. Sudjelovalo je 100 ispitanika, a vrijeme provedbe je bilo u periodu od 2013. do 2016. godine. Rezultati su pokazali da je kognitivni poremećaj utvrđen u $69 \%$ pacijenata te da je dob neovisan rizični čimbenik za kognitivni poremećaj prema MoCa testu. Za svaku godinu života povećan je rizik od kognitivnog poremećaja za 19 \% (17). U KBC-u Osijek istraživana je i učestalost nesuradljivosti pri uzimanju lijekova kod hemodijaliznih bolesnika. Nesuradljivost prilikom uzimanja lijekova nađena je kod trećine ispitanika. Njih $68 \%$ tijekom tjedna koje je prethodilo istraživanju, nije propustilo uzeti propisani lijek te su svrstani u skupinu onih koji su bili suradljivi (18). Rezultati istraživanja o prehrambenim navikama hemodijaliznih bolesnika provedenog u tri centra (Poliklinika za internu medicinu Avitum, KBC Rijeka i KB Merkur) na uzorku od 92 ispitanika dali su vrijedne podatke koji se mogu primijeniti u svakodnevnom radu. Zaključeno je kako postoji još prostora za poboljšanje navika te da se edukcijom bolesnika i ograničenjima u prehrani isti mogu dobro i kvalitetno hraniti. Potreban je individualni pristup pacijentu radi različitih navika i nutritivnih potreba svakoga bolesnika (19).

\section{ZAKLJUČAK}

Analizom literature zaključeno je da još uvijek ne postoji jasno definirana međunarodna klasifikacija bolesnikove sigurnosti. U većini odjela za nefrologiju odsutne su smjernice o pružanju skrbi za hemodijalizne pacijente. Jedan od najčešćih problema kod pacijenata na hemodijalizi je seksualna disfunkcija o kojoj se rijetko progovara, a prostor za rješavanjem problema otvara se u edukaciji medicinskih sestara i samih pacijenata. Podrška u zajednici, a ponajprije obitelji, izrazito su važan izvor potpore pacijentima na hemodijalizi. U procesu liječenja neophodni su: odgovarajući prostorni uvjeti, pridržavanje propisa od strane pacijenata te edukacija i praćenje stručnih smjernica osoblja i pacijenata. Zdravstveni sustav treba omogućiti oboljelim što veći stupanj neovisnosti, razvoj vještina samopomoći i mehanizama suočavanja sa svim negativnim posljedicama liječenja.

\section{LITERATURA}

1. Kes P. Trajno nadomještanje bubrežne funkcije. Zagreb; 2011.

2. Ronco C, Chezzi PM, Lagreca G. The role of technology in hemodialysis. J Nephrol. 1999;12:6881.

3. Fučkar G. Sestrinsko medicinski problem: uvod u sestrinske dijagnoze. Zagreb; 1996.

4. Halovanović G. Anksioznost u bolesnika na liječenju kroničnom dijalizom: opća bolnica Ogulin. Hrvatska; 2015;166-169.

5. Tsai SH, Wang MY, Miao NF, Chian PC, Chen $\mathrm{TH}$, Tsai PS. The efficacy of a nurse -led breathing training program in reducing depressive symptoms in patients on hemodialysis: a randomized controlled trial. Am J Nurs. 2015;115(4):24-32.

6. Hollander E. Anksiozni poremećaji. Naklada Slap; 2006.

7. Hrvatski registar nadomještanja bubrežne funkcije: Hrvatsko društvo za nefrologiju, dijalizu i transplataciju. 2008.

8. Mrduljaš-Đujić N. Kvaliteta života bolesnika na dijalizi. Split: Acta Med Croatica; 2016;70:225232.

9. Bahadori M, Ghavidel F, Mohammadzadeh S, Ravangard $\mathrm{R}$. The effects of an interventional program based on self-care model on health-related quality of life outcomes in hemodialysis patients. J Educ Health Promot. 2014;29:3-10.

10.Bednar B, Latham C. The changing landscape of the nephrology nursing care environment in 
the United States over the last 45 years. Nephrol Nurs J. 2014;41:183-90.

11. Van Ek GF, Gawi A, Nicolai MPJ, Krouwel EM, Den Oudsten BL . Sexual care for patients receiving dialysis: A cross-sectional study idenntifying the role of nurses working in the dialysis department. J Adv Nurs. 2018;74:128-36.

12. Van Ek GF, Krouwel EM, Nicoalai MPJ, Den Oudsten BL. What is the role of nephrologists and nurses of the dialysis department in providing fertility care to CKD patients. Int Urol Nephrol. 2017;49:1273-85.

13. Vioulac C, Aubree C, Massy ZA, Untas A. Empathy and stress in nurses working in haemodialysis. J Adv Nurs. 2016;72:1075-85.

14. Farias de Queiroz Frazao CM, de Almeida Medeiros AB, Mariano Nunes de Paiva Md. Nursing diagnoses and adaptation problems among chronic renal patients. Invest Educ Enferm. 2015;33:119-27.
15. Saunders S, MacLeod ML, Salyers V, MacMillan PD, Ogborn MR. Anaemia management protocols in the care of haemodialysis patinets: examining patient outcomes. J Clin Nurs. 2013;22:2206-15.

16. Raguž D. Sigurnost bolesnika na bubrežnom nadomjesnom liječenju hemodijalizom te pojavnost sestrinsko medicinskih problema. Sveučilište u Splitu: Split; 2014;9-17.

17. Logarušić D. Procjena kognitivnog statusa bolesnika liječenih kroničnom hemodijalizom uz pomoć Montrealske ljestvice kognitivnih sposobnosti-MoCA test. Sveučilište u Osijeku: Osijek; 2016;9-26.

18. Bart D. Suradljivost pri uzimanju lijekova u bolesnika na kroničnoj hemodijalizi. Sveučilište u Osijeku: Osijek; 2017;9-19.

19. Mateljić R. Prehrambene navike bolesnika liječenih hemodijalizom. Sveučilište u Zagrebu: Zagreb; 2014;12-32. 


\title{
THE ROLE OF NURSING CARE IN HEMODIALYSIS PATIENTS
}

\author{
Julija Krstanović, Roberta Perković, Joško Petričević \\ Faculty of Health Studies, University of Mostar, Mostar, Bosnia and Herzegovina
}

\begin{abstract}
INTRODUCTION: Today, as a result of great progress in the treatment of hemodialysis, patients with chronic renal failure can live longer. Quality cooperation, patient adaption and effective compliance with healthcare recommendations are the basis for a quality hemodialysis process with minimal complications.

OBJECTIVE: The objective of this study is to examine the effect of proper provision of nursing care in hemodialysis patients on the quality of the hemodialysis process and incidence of complications.

SUBJECTS AND METHODS: We used the following methodology: a search of the biomedical database PubMed and a survey of latest research in the last five years from Google Scholar. We selected and analysed 9 clinical studies according to keywords from the title and abstract.

RESULTS: The majority of nephrology departments do not have guidelines for the provision of nursing care for hemodialysis patients. Sexual dysfunction is a problem that is rarely mentioned and education of healthcare professionals is something that would help resolve this problem. Lack of cooperation during medication administration and development of cognitive disorders are common problems among hemodialysis patients.

CONCLUSION: Community support, above all family support is an extremely important source of support for hemodialysis patients. The healthcare system should provide a higher degree of independence, development of self-help skills and mechanisms for coping with negative consequences of the treatment.
\end{abstract}

Key words: nurse, health care, hemodialysis, patient

Corespondence:

Julija Krstanović, prvostupnik sestrinstva

E-mail: krstanovic.julija93@gmail.com 